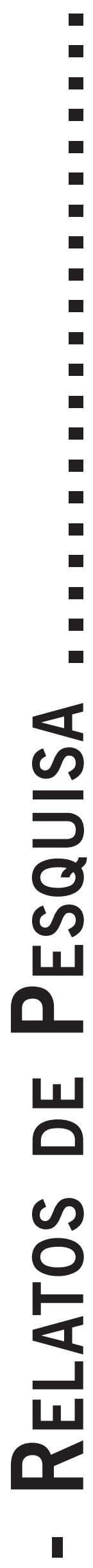




\title{
O CONTATO NA SITUAÇÃO CONTEMPORÂNEA: UM OLHAR DA CLÍNICA DA GESTALT-TERAPIA
}

\author{
Contact Nowadays: a Clinical Look of Gestalt therapy
}

Contacto en la Contenporaneidad: una Mirada de la Clínica de la Terapia Gestalt

\author{
Thatiana Caputo Domingues da Silva \\ Camilla Santos Baptista \\ MÔNICA BotelHo Alvim
}

\begin{abstract}
Resumo: Este artigo parte das queixas trazidas pelos clientes para nossa clínica e busca a partir daí uma compreensão sobre a existência no mundo contemporâneo e como vivenciamos o contato com o outro na atualidade. Para isso, fazemos uma revisão bibliográfica nos debruçando sobre o que a Gestalt-Terapia fala a respeito das relações e do homem. Articulamos essa visão com o que vemos hoje em nossa sociedade, através de um diálogo com autores que abordam o tema da contemporaneidade. A partir de nossos estudos pudemos perceber que os sofrimentos com os quais nos deparamos apontam para uma dificuldade do estabelecimento do diálogo, da intimidade e da entrega, que se configuram para a Gestalt-Terapia como interrupções na dinâmica do contato, nomeadamente nas etapas do contato e do contato-final. Concluímos que essas dimensões, necessárias para o contato, para o estabelecimento de uma relação plena com o outro, parecem não estar encontrando lugar em nossa sociedade, o que pode estar ligado a uma crescente perda do espaço da experiência. Isso se expressa na dificuldade de vivenciar dimensões imprescindíveis para que a experiência ocorra, como a da pausa e a da entrega, da abertura e da disponibilidade, do risco implícito nas relações com o outro.
\end{abstract}

Palavras-chave: Gestalt-terapia; Clínica; Contato; Contemporaneidade; Experiência.

\begin{abstract}
This article was motivated by the complaints brought from the clients to our clinic and search from there an understanding about the existence in the contemporary world and how we experience the contact with each other today. For this, we make a literature review discussing what Gestalt Therapy think about relationships and men. Furthermore, we articulate that vision with what we see today in our society through a dialogue with authors who discuss issues of contemporaneity. From our studies we realized that the sufferings we encounter speaks about difficulties in the establishment of dialogue, intimacy and surrender, which configures itself to the theory of Gestalt Therapy as interruptions in the dynamics of the contact, named as the steps of: contact and final contact. We conclude that these dimensions needed for the contact, to establish a full relationship with others, seem not to be finding place in our society, which can be linked to an increasing loss of the experience space. This is expressed in the difficulty of living dimensions essential to the establishment of experience, such as respite and surrender, openness and availability, the risk implicit in relationships with others.
\end{abstract}

Keywords: Gestalt Therapy; Clinic; Contact; Contemporary; Experience.

Resumen: Este artículo fue motivado por las quejas presentadas por los clientes a nuestra clínica y búsqueda a partir de ahí un entendimiento acerca de la existencia en el mundo contemporáneo y cómo experimentamos el contacto con los demás hoy. Para ello, hacemos una revisión de la literatura abordando lo que la Terapia Gestalt habla de las relaciones y los hombres. Acercamos esta visión con lo que vemos hoy en día en nuestra sociedad, a través de un diálogo con los autores que abordan el tema de la contemporaneidad. A partir de nuestros estudios nos dimos cuenta de que los sufrimientos con la que nos enfrentamos indican una dificultad de establecer el diálogo, la intimidad y la entrega, que están configurados para la Terapia Gestalt como interrupciones en la dinámica de contacto, a saber las etapas de contacto y el contacto final. Llegamos a la conclusión de que estas dimensiones necesarias para el contacto, para establecer una relación plena con el otro, parecen no estar encontrando su lugar en nuestra sociedad, lo que puede vincularse a una creciente pérdida del espacio de la experiencia. Esto se expresa en la dificultad de experiencia de las dimensiones esenciales para la experiencia se producir, como la pausa y el la entrega, la apertura y la disponibilidad de los riesgos en relación con los demás

Palabras clave: Terapia Gestalt; Clínica; Contacto; Contemporaneidad; Experiencia.

\section{Introdução}

A Gestalt-terapia considera que o homem e todo organismo vivo está interligado com o resto do mundo; não faz sentido falar do homem isoladamente, mas sim de um homem que vive em um determinado meio que faz parte de sua existência e forma com ele uma totalidade. Seu foco não se encontra nem no sujeito nem no ambiente, mas na relação, no encontro organismo-ambiente. Essa forma de pensar aponta para uma superação de uma visão dicotômica e para uma proposta de psicologia que vai se debruçar no estudo do contato em si, dessa 
fronteira que interconecta eu-mundo, eu-outro. É nesse sentido que para a Gestalt-Terapia o self é contato. Sendo definido como sistema de contatos o eu é deslocado do interior do psiquismo para o campo, não é compreendido como substância, mas como um processo que se desenrola no tempo, uma espontaneidade expressiva e criadora (Alvim, 2012).

Entende-se que a fronteira marca uma delimitação temporal e indica o momento em que nos deparamos com uma novidade que nos causa estranhamento e nos faz partir em busca de um sentido para este encontro. A experiência é entendida aqui como uma operação criadora e expressiva que ocorre a partir da tensão pelo encontro com a novidade do ambiente. Dessa forma, falar de experiência é falar essencialmente de contato, desse processo de encontro e assimilação de uma diferença, que implica em arriscar-se diante novo, do desconhecido. O que para a Gestalt-Terapia se chama ajustamento criativo.

Esse processo consiste numa ação espontânea no campo que opera em modo médio, nem ativo nem passivo. "O espontâneo é tanto ativo quanto passivo, tanto desejoso de fazer algo quanto disposto a que lhe façam algo; ou melhor, está numa posição equidistante dos extremos (...), uma imparcialidade criativa" (Perls, Hefferline \& Goodman, 1951/1997, p. 182). Em consonância com a Gestalt-Terapia, Bondía discorre:

(...) o sujeito da experiência se define não por sua atividade, mas por sua passividade, por sua receptividade, por sua disponibilidade, por sua abertura. Trata-se, porém, de uma passividade anterior à oposição entre ativo e passivo, de uma passividade feita de paixão, de padecimento, de paciência, de atenção, como uma receptividade primeira, como uma disponibilidade fundamental, como uma abertura essencial (2002, p. 24).

Esses aspectos parecem ser justamente aquilo que está em falência na contemporaneidade: a possibilidade do contato pleno, da entrega, da abertura, da awareness. Isso faz com que consideremos que a Gestalt-Terapia pode nos auxiliar a olhar de forma mais crítica para os fenômenos que vêm ocorrendo na atualidade e em nossa clínica.

Assim, pretendemos estudar neste trabalho os valores da sociedade atual que atravessam os dilemas que são trazidos pelas pessoas para nossa clínica, pretendendo desse modo ampliar a visão do que se passa dentro do consultório para além do psiquismo, fugindo de um psicologismo. Reafirmamos uma posição dialética fundada no diálogo e na relação, na tentativa de ultrapassar uma prerrogativa individualizante e parcial na consideração do fenômeno humano.

\section{A experiência do contato: do eu-outro, para o nós}

É como se eu fosse vermelho e ele amarelo, eu só queria que de vez em quando virássemos laranja e depois voltássemos a ser vermelho e amarelo e assim por diante. Stela

A frase em epígrafe, dita e repetida por Stela (nome fictício) durante a terapia, nos oferece pistas para a compreensão de seu sofrimento e desejo de estabelecer uma relação de encontro pleno. Sente-se solitária e frustrada em suas tentativas de interação e de intimidade. Stela aparece aqui como um exemplo que se repete em nossos consultórios e que parece se multiplicar, nos levando a buscar compreender como as pessoas estão fazendo contato.

Antes de começarmos a explorar este tema, torna-se importante apontar que na literatura da Gestalt-Terapia existem muitas formas de se olhar para o contato e suas interrupções. Os próprios modos de pensar essa dinâmica têm uma função mais didática do que representativa da realidade e a intenção da teoria ao falar dos tipos de interrupção não é a de criar uma grade teórica na qual devemos encaixar todos os indivíduos. Trata-se de uma "concepção para manter [o terapeuta] orientado, para saber em que direção olhar. É o hábito adquirido, o pano de fundo para esta arte, como qualquer outra" (Perls, Hefferline \& Goodman, 1951/1997, p. 249).

\section{0 processo de contato e suas interrupções}

Para abordar o contato e a forma como ele acontece no desenrolar do tempo os fundadores da Gestalt-terapia propuseram quatro etapas: pré-contato, contato, contato final e pós-contato. Como recorte de nosso estudo, de maneira a nos ater aos casos que mais apareceram em nossa clínica, vamos nos debruçar sobre as etapas do contato e o contato final.

Quando melhor analisamos as demandas que chegaram até nós, percebemos que todas parecem, antes de tudo, apontar certa dificuldade na experiência da alteridade e do diálogo. Toda neurose, em algum nível, é a substituição do desconhecido e do diferente pelo conhecido em uma tentativa de evitação frente a algo que nos ameaça. Sem diferença, entretanto, não há contato e na tentativa de nos livrarmos da ansiedade diante do novo, da "vertigem da liberdade" (Miller, 1990, p. 12), estamos cada vez mais adoecidos.

A forma como se interrompe a dinâmica de contato fala da singularidade daquela pessoa e mostra o momento em que se bloqueia o fluxo da experiência, onde a dificuldade parece estar mais presente. Acreditamos haver algo em nosso contexto atual que se relacione de forma dialética com os indivíduos para que as interrupções que ocorrem 
no momento do contato e do contato final - retroflexão, proflexão e egotismo - apareçam de forma tão marcante.

\subsection{Contato}

Na etapa do contato a energia mobilizada já está comprometida, isto quer dizer que já houve a eleição de uma figura, o organismo teve uma sensação, se conscientizou de sua necessidade, se mobilizou e agiu em direção a uma possível satisfação. O momento é o da agressão, de lidar com a diferença e com o outro, envolve conflito, destruição e assimilação do novo, dessa figura escolhida para a satisfação de uma necessidade.

É, portanto, o momento do embate vigoroso, da nutrição, onde o self, frente a um conflito, ao lançar-se completamente no processo de assimilação, passa a se perceber e a estar mais aware de si. Trata-se de um momento em que como a figura já está escolhida e a energia comprometida, o organismo encontra-se na iminência da interação em si. Quando o bloqueio se dá nesta etapa, a energia que estava sendo direcionada para a figura retorna - em um ato de trazer para si aquela energia direcionada para o exterior - ou é direcionada ao outro, só que de forma enviesada. Estas duas possibilidades que descrevemos são respectivamente o que chamamos de retroflexão e proflexão, que falam de uma impossibilidade da pessoa de expressar suas necessidades para o outro de forma direta. Essa dimensão comum que une tanto a retroflexão quanto a proflexão nos faz pensar o quanto essas interrupções caracterizam justamente uma impossibilidade de agir com espontaneidade frente ao outro, de encontrar e trocar com este diretamente, com confiança e coragem de assumir o risco que isso inclui.

O conflito direto é evitado e as formas disponíveis para se tentar alguma satisfação passam a ser: ou satisfazer a si mesmo ou uma tentativa de eliciar no outro uma resposta mais ou menos esperada. Nas duas formas o outro passa a ser nebuloso e distante e o organismo encontra-se isolado. Na retroflexão, esse isolamento é marcado por uma autossuficiência, um fazer você mesmo, enrijecendo a fronteira de contato e cindindo-se do ambiente, do outro; e na proflexão há uma espécie de "cegueira” e o outro passa a ser como uma tela de projeção, fantasiado, um espectro enevoado no qual se vê apenas uma idealidade.

Assim, nem quando se funciona retrofletindo, nem quando se funciona profletindo, se consegue pedir aquilo que se deseja. Ambas são formas de atividade. No primeiro caso, há uma desistência do outro ou se entende que precisar dele é uma fraqueza, fazendo consigo mesmo aquilo que se precisa. Já na proflexão, toma-se o outro como objeto, de modo a satisfazer a sua necessidade. Para isso, utiliza-se de manipulação, de comportamentos evocativos e indiretos, redobrando seus esforços quando encontra alguma resistência. Dessa forma, suas relações se mantêm empobrecidas, sem a sensação de estar satisfeito.

\subsection{Contato final}

O contato final é o ápice do processo do contato, porém, não chega a ser o seu final em si, já que este acontece no pós-contato, momento da assimilação e do crescimento. Trata-se, então, do momento da união, do encontro eu-figura em si. Segundo Clarkson (1989) esse é o momento do engajamento total, cheio e vibrante com a figura da ação escolhida.

No contato final o self está absorvido de maneira imediata e plena na figura que descobriu-e-inventou; no momento não há praticamente nenhum fundo. A figura incorpora todo o interesse do self, e o self não é nada mais do que seu interesse presente, de modo que o self é a figura (Perls, Hefferline \& Goodman, 1951/1997, p. 221).

Nesse momento finalmente relaxa-se a deliberação; o sentimento de ego ativo que pode ter havido na fase anterior, quando se estava ainda na etapa do conflito e da agressão, abranda-se e desaparece. "E há por alguns momentos, apenas a figura e o sentimento de espontaneidade, com o fundo vazio" (Perls, Hefferline \& Goodman, 1951/1997, p. 216).

Dizer que o fundo está vazio indica que por alguns momentos o eu desliga-se de si mesmo, de sua sensação de ser um self separado do mundo e do outro, de suas significações sobre si, para então se entregar totalmente à figura construída. Fala-se, portanto, em certa passividade que envolve esse ato de entrega. Em um abdicar de si, desse "eu" pronto e fechado, para se deixar ser totalmente com a figura escolhida, para se permitir "afundar inteiramente em seu sentimento de atenção: falamos de ser 'todo ouvidos', 'todo olhos”' (Perls, Hefferline \& Goodman, 1951/1997, p. 222). A figura ocupa todo o campo do self e nesse momento há a possibilidade do "Eu-Tu se transformar momentaneamente em um Nós" (Robine, 2006 p. 131).

É um momento em que o self está completamente absorvido pela figura que descobriu-e-inventou e, para ele, não existe mais nada além dela. Há uma dedicação completa e, naquele instante, não há outras possibilidades, não se pode escolher de outra forma. Como bem disse Stela no início de nosso capítulo, este é o momento em que se sai da cor vermelha, se integra ao amarelo e se entrega ao laranja. Para depois voltar a ser vermelho e amarelo.

Em todo o processo de contato há uma unidade subjacente de funções perceptivas, motoras e de sentimento (...). Mas talvez seja somente no contato final com sua espontaneidade e absorção, que essas funções são todas primeiro plano, elas são a figura: estamos conscientes da unidade. Isto é, o self (que nada mais é do que contato) passa a sentir a si mesmo. 
E o que está sentindo é o processo de interação entre organismo e ambiente (Perls, Hefferline \& Goodman, 1951/1997, p. 221-222).

Isso implica que esse momento, no qual estamos nos debruçando, é aquele derradeiro para se experienciar tanto o outro quanto a si mesmo. É o momento em que se pode sentir mais claramente a nossa qualidade de totalidade, de campo-organismo-ambiente, de uno, superando uma concepção de homem como um ser separado do mundo. Talvez seja apenas nessa etapa do contato que podemos estar mais conscientes da nossa qualidade holística primordial. É na mais profunda experienciação de renúncia de si, de entrega, que o self se sente mais vivo: "A experiência é inteiramente intrínseca, e de maneira alguma estamos agindo de modo deliberado em relação a ela. O relaxamento da deliberação e o desaparecimento das fronteiras é a razão da vividez e do vigor extras" (Perls, Hefferline \& Goodman, 1951/1997, p. 221). Aqui ocorre um processo de dissolução das fronteiras em prol do surgimento de uma terceira figura que surge do encontro entre eu-outro, organismo-ambiente nesse momento de ápice do contato. Essa figura fornece sua própria fronteira a partir deste encontro.

A impossibilidade de se exercer esse ato de entrega, ou como diria Robine, de se soltar, é chamada pela literatura de egotismo. Segundo Perls, Hefferline \& Goodman (1951/1997) consiste numa dificuldade em renunciar ao controle e à vigilância, numa ansiedade frente à indiferenciação, numa preocupação última com nossas próprias fronteiras, consigo ao invés de com aquilo que é contatado. Há uma dificuldade em "relaxar o controle, soltar-se, ter a audácia de terminar a ação empreendida, abrir as fronteiras ao encontro" (Robine, 2006 p. 131). Consiste também, numa tentativa de se ter certeza de que todas as possibilidades do fundo foram exauridas antes de se comprometer e com isso impedir a ameaça da surpresa.

O self, ao se enrijecer e evitando se entregar, não consegue agir em sua dimensão de espontaneidade e criatividade. Ele se vê em uma situação de emergência em cada possibilidade de interação e por isso mesmo precisa se proteger. Ao estar impedida justamente essa dimensão mais primeira do self, a espontaneidade, o que acontece é a perda da possibilidade de agir fora dos extremos da atividade ou da passividade. $\mathrm{O}$ que não permite vivenciar plenamente o encontro, ficando o contato esquecido enquanto possibilidade.

Ao tocarmos nesse ponto nos deparamos com o que consideramos ser a chave para a compreensão do que pode ser uma possibilidade de resgate da dimensão da experiência. Parece que o que falta, tanto nos indivíduos como em nossa sociedade, é justamente esse modo de estar no mundo nem ativo, nem passivo, um modo médio ou intermediário. Esse parece ser o cerne da dificuldade presente em grande parte no modo de existir das pessoas que vêm chegando aos nossos consultórios.

\section{A experiência na contemporaneidade}

Ao falar do contemporâneo, podemos pensar tanto no período específico atual da história do mundo, como na pessoa que vive este tempo. Agamben (2009) traz uma importante contribuição neste sentido ao propor e se referir ao homem contemporâneo não como aquele que vive no seu tempo, mas como aquele que não coincide inteiramente com o tempo em que vive, nem está adequado às suas prescrições. Não por que viva em outro tempo, mas por que este deslocamento ao qual se refere o torna, mais que qualquer outro, capaz de perceber e apreender o seu tempo. Haveria então uma distância necessária para que, vivendo neste tempo, possamos tomá-lo como objeto de nossa reflexão. Com isso, podemos pensar em duas formas de existir no tempo presente, uma alienada, acrítica, apartada de uma reflexão sobre o mundo atual, e outra, a qual Agamben chama de contemporânea, que é a vivência daquele que "mantém fixo o olhar no seu tempo, para nele perceber não as luzes, mas o escuro" (2009, p. 62) isso não significa de modo algum uma inércia, mas sim, como acrescenta ele, "uma habilidade particular, que nesse caso, equivalem a neutralizar as luzes que provêm da época para descobrir as suas trevas, o seu escuro especial, que não é, no entanto, separável daquelas luzes” (2009, p. 63).

Em uma tentativa de assumir uma postura contemporânea, tal qual Agamben se refere, podemos partir, então, para pensarmos um pouco sobre esse tempo que vivemos e construímos.

\subsection{Marcas da contemporaneidade}

Fazendo referência ao termo utilizado por Freud, podemos falar hoje em um "mal-estar" na contemporaneidade. Este mal-estar pode ser pensado em diversos âmbitos e neste artigo elegemos alguns sobre os quais achamos importante nos debruçar - a perda das referências, o racionalismo e o cientificismo, o incremento do individualismo, a aceleração do tempo. Para isso, faz-se necessário recuarmos um pouco na história e lançarmos um olhar sobre esse período que sucedeu a queda do Antigo Regime, o qual chamamos de modernidade.

A modernidade, nascida com a ilustração, teria privilegiado o universal e a racionalidade; teria sido positivista e tecnocêntrica, acreditado no progresso linear da civilização, na continuidade temporal da história, em verdades absolutas, no planejamento racional e duradouro da ordem social e política; e teria apostado na padronização dos conhecimentos e da produção econômica como sinais da universalidade (Chauí 2007, p. 489).

Esses foram processos graduais, que se iniciaram na passagem da Idade Média para a Idade Moderna, onde 
Deus perdeu o lugar de centralidade que ocupava e o homem foi colocado no centro do Universo. Com a perda das referências oferecidas pela Igreja como fontes de poder, a racionalidade passa a conferir ao homem uma segurança. $\mathrm{O}$ desconhecido se tornou ameaçador e a busca pelo controle se apresentou como saída para lidar com o medo deste. O homem passa, então, a buscar na sua própria razão e na ciência formas que lhe possibilitem prever o futuro e desvendar os mistérios do desconhecido.

Ainda hoje vemos resquícios desse racionalismo e cientificismo arraigados em nossa sociedade. A ciência parte em busca de leis gerais, com pretensões universalizantes, e com isso contribui para que a diferença perca cada vez mais lugar. Ao longo da história, corpo e mente foram separados numa dualidade aparentemente irreconciliável. Opondo-se de um lado o movimento racionalista, representado por Descartes - que considerava que o corpo era fonte enganosa de sentidos e que a verdade só poderia ser acessada através do pensamento - e de outro o empirista, representado por Hume - que considerava que o conhecimento se dava a partir dos sentidos que respondiam a estímulos externos (Alvim, Araújo, Baptista, Barroso, Queiroz \& Da Silva, 2012).

Com a fenomenologia um espaço é aberto e se torna possível romper com alguns dualismos. Começa-se a pensar que consciência e mundo não são separados, mas aspectos de uma mesma realidade, na qual corpo e mente estão associados numa experiência intencional. Merleau-Ponty vem afirmar que a consciência é corporal, que toda experiência é fundamentalmente perceptiva e os processos representativos se dão sempre $a$ posteriori. Afirma que a consciência reflexiva não é nem a primeira, nem a única forma da consciência, esta depende da consciência perceptiva, que não se discerne de um corpo cognoscente (Merleau-Ponty, 1946/1990).

Em sua obra "Vigiar e Punir", Foucault (2007) afirma que os séculos XVIII e XIX foram marcados por um processo de dominação que se apropriou desse corpo como objeto e alvo de poder, através da disciplinarização. Este processo, conhecido como docilização dos corpos, operou transformando o homem em "corpo-máquina”. "Esses métodos que permitem o controle minucioso das operações do corpo, que realizam a sujeição constante de suas forças e lhes impõem uma relação de docilidade-utilidade, são o que ele denominou 'disciplinas”' (Alvim, 2013).

É importante falarmos também da mudança do papel do Estado. Segundo Dufour (2005) a figura do governo enquanto instituição cuja legitimidade é externa aos interesses econômicos está ausente nos dias de hoje. Assim, abole-se a autoridade e torna-se oculto o poder, vive-se uma "tirania sem tirano". Isso marca um novo "darwinismo social", onde aqueles "mais adaptados" podem tirar proveito das situações mais diversas, e aqueles "menos adaptados" são abandonados ou mesmo convocados a desaparecer. Parece não mais ser atribuído ao Estado o de- ver de prover e proteger a população. Sozinho, o sujeito passa a ser responsável pelo seu próprio bem estar; esse "cada um por si" colabora para uma desarticulação do fazer coletivo e um isolamento dos sujeitos.

No neoliberalismo - modelo econômico que marca nosso tempo como um desdobramento pós-moderno do liberalismo - o imperativo é que as mercadorias circulem, o que promove outro imperativo, o do hedonismo individualista travestido de liberdade. Dessa forma, o novo capitalismo oferece um "perfume libertário" a esse discurso, que se funda na proclamação da autonomia de cada um. Não se trata apenas de um "menos-Estado", mas de um menos tudo o que entravar esse fluxo de mercadoria.

Recorrendo a Nietzsche, Dufour (2005) ressalta que a sociedade pós-moderna apresenta um 'niilismo cansado', em que os valores tornam-se cinzentos. Neste niilismo esgotado dá-se um lugar central ao que tranquiliza, entorpece, alivia, cura, sob vestimentas diversas. Em nossos dias essa posição chave seria ocupada pela mercadoria, que faz circular objetos no lugar do "nada ontológico" em que repousa a sociedade.

Nesse panorama observamos outra das principais marcas da sociedade contemporânea, o individualismo, que traz uma concepção do homem enquanto separado do coletivo, valorizando o que é da ordem do individual. O outro é visto como ameaçador e passa, então, a ser aceito por nós apenas quando reproduz nossa individualidade. Parte de sua dimensão de alteridade é descartada. Esse outro que ao mesmo tempo é semelhança e diferença, é negligenciado enquanto diferença. Mas é justamente enquanto outro, enquanto não-eu, que ele pode me tocar, me atingir, descentrar, convidando-me a desnaturalizar minhas próprias significações e promovendo, a partir de sua diferença, uma mobilização dos meus sentidos já instituídos.

Num ensaio em que discute o "viver junto", Franklin Leopoldo e Silva (2012) nos lembra de uma célebre frase de Jean Paul Sartre, em que este afirma que o inferno são os outros. Segundo o autor viver junto implica numa partilha de valores sobre a vida, aspirações comuns, ou seja, um movimento em direção a uma vida comum, uma convivência. Contudo, é justamente esta a dimensão prejudicada em nossa sociedade. Essa dimensão do convívio, do comum, no sentido de uma comunhão. Sob o discurso da tolerância, aprendemos não a aceitar o outro, mas sim a relegá-lo à sua solidão, com a expectativa de que ele nos permita viver a nossa. A vida em sociedade não envolve a solidariedade, o que faz com que a solidão seja uma constante da nossa época. Sobre isso, Leopoldo e Silva (2012) afirma:

A solidão numa sociedade massificada encoraja o indivíduo a buscar alívio e abrigo em grupos sectários, nos quais a homogeneidade representa a segurança que não está presente na experiência autêntica da diversidade. Nesses agrupamentos restritos e 
de convicções predefinidas, vigora um simulacro de solidariedade que, de fato, não é outra coisa senão a uniformidade de pensamento, portanto, a ausência de liberdade (p. 12).

Para que a diversidade do encontro com a diferença possa ser experienciada autenticamente, como propõe Leopoldo e Silva, é necessário estarmos abertos à dimensão do risco. Bondía (2002) entende como experiência aquilo que nos passa, nos acontece, nos toca, o que é cada vez mais raro nos dias atuais. Ele defende que para que haja a experiência, dentre outras coisas, é necessário que haja uma exposição, um risco.

A própria etimologia da palavra experiência nos mostra que ela comporta duas dimensões inseparáveis, uma de travessia (raiz per) e outra de perigo (radical periri). Bondía (2002) cita um trecho de Heidegger onde este traz uma definição de experiência que se afina com a ideia de uma exposição, uma receptividade e uma abertura, assim como as dimensões de travessia e perigo.

(...) fazer uma experiência com algo significa que algo nos acontece, nos alcança; que se apodera de nós, que nos tomba e nos transforma. Quando falamos em "fazer" uma experiência, isso não significa precisamente que nós a façamos acontecer, "fazer" significa aqui: sofrer, padecer, tomar o que nos alcança receptivamente, aceitar, à medida que nos submetemos a algo. Fazer uma experiência quer dizer, portanto, deixar-nos abordar em nós próprios pelo que nos interpela, entrando e submetendo-nos a isso. Podemos ser assim transformados por tais experiências, de um dia para o outro ou no transcurso do tempo (Heidegger, como referido em Bondía, 2002, p. 6).

O sujeito da experiência, tanto para Bondía, quanto para Heidegger é um sujeito "alcançado", "tombado", "derrubado". O oposto desse ideal propagado pela sociedade contemporânea, de um homem que permanece de pé, seguro de si, que alcança aquilo que se propõe, que se apodera daquilo que quer, que é definido pelos seus poderes e seus sucessos. Diferente disso, o sujeito da experiência perde seus poderes justamente por que aquilo de que faz experiência dele se apodera.

Partindo então desta concepção de experiência, parece-nos que ela tem tido cada vez menos espaço em nossa sociedade. Um dos fatores que colabora para este quadro é a falta de tempo. Vivemos uma crise na experiência do tempo e do espaço, onde a velocidade é uma marca inegável. Essa experiência do tempo como uma vivência instantânea, pontual e fragmentada passa sem deixar vestígios e essa velocidade que caracteriza a contemporaneidade impede a conexão significativa entre os acontecimentos. Assim, é como se esses fossem retalhos soltos que não chegam a ser costurados, perdendo-se da sua totalidade, da sua colcha de sentidos.
Nesse nosso afã por rapidez e utilidade aquilo que demanda tempo não tem mais vez, e experiência, diálogo, intimidade, tem um tempo singular que não segue o tempo estipulado de fora. Essa falta de tempo massificada, essa correria desenfreada traz sujeitos arfantes aos nossos consultórios. Eles querem soluções também mais rápidas, querem uma cura sem esforço, pois esforço também demanda um tempo que eles, tampouco nós, temos.

A velocidade parece ter virado um modo massificado de deflexão do medo da incerteza, do desconhecido, do não passível de controle, do inesperado. E, nesse sentido, o outro, na sua dimensão de diferença, parece ter se tornado uma ameaça ao nos remeter sempre ao desconhecido, ao mistério que não temos como prever. O outro enquanto diferença assusta e intimida; correndo, temos a ilusão de nos livrarmos da ansiedade de estar frente a algo tão arrebatador, que tem o potencial de nos descentrar, de retirar o controle que acreditamos possuir. "Porque o que nos recusamos a pensar é a diferença, a alteridade, a incômoda e próxima presença do outro, que a todo dia nos confronta cara a cara, que se nos oferece como margem irrecusável e intransponível” (Giacoia Jr, 2012, p. 8).

Esse outro que nos confronta é também aquele que pode nos confirmar e que nos oferece a possibilidade de um vínculo e de uma vida comum, da saída da nossa solidão. Isso implica que esse outro apresenta duas dimensões, uma de singularidade e outra de generalidade. Merleau-Ponty (1962) afirma que essas duas dimensões da alteridade só podem ser compreendidas como uma tensão. Notamos que na atualidade há uma dificuldade na manutenção desta tensão, acabamos tendendo sempre para um dos polos. Sobre isso, Santos (2009, p. 18) afirma: "Temos direito a ser iguais quando a diferença nos inferioriza; temos direito a ser diferentes quando a igualdade nos descaracteriza".

\section{Entrecruzamentos}

Até aqui nos detivemos em descrever como a Gestalt-Terapia entende as relações humanas, como estas têm aparecido em nossa prática clínica e a situação contemporânea de onde emergem. Se somos, como dizia Merleau-Ponty (1964/2000), a carne do mundo, se comungamos de um fundo comum, de uma generalidade, de uma cultura que nos atravessa a todos, podemos inferir que não é à toa que muitos estamos adoecidos. Compartilhamos de uma teia também adoecida, de um fundo que não é favorável à experiência de alteridade, ao encontro, à intimidade, à singularidade, à criação de novos possíveis.

Vimos, em nossa clínica, que as pessoas têm tido cada vez mais dificuldade em lidar com o momento do conflito e da entrega. Como dissemos no início deste artigo, a dificuldade do conflito é uma dificuldade do embate, da agressão; e a da entrega diz respeito a abrir mão de uma 
atividade, de se lançar na experiência de união e dissolução das fronteiras. Em última instância, ambas remetem a uma dicotomização dos polos atividade e passividade, ora uma valorização da atividade em detrimento da passividade ora uma sujeição passiva. Esta última, no entanto, parece bemvinda quando a serviço de uma docilização, quando incentiva formas acríticas e introjetoras de existir no mundo.

Dessa forma, podemos estar em uma atividade mecânica, guiada pela pressa, que reflete uma lógica de produtividade e um medo de parar e encarar a ansiedade da incerteza frente ao desconhecido e/ou podemos estar também num modo de ser passivo, engolindo pronto aquilo que vem de fora. Em ambos os casos alienados e acríticos, o que permeia esses dois modos de estar no mundo é uma alienação tanto pela atividade quanto pela passividade.

Esses modos de ser não existem separadamente, pelo contrário, é como se houvesse a necessidade da alienação pela passividade, pela docilização desse corpo que, disciplinado, introjeta os valores dessa sociedade para que então os execute ativamente. Os sujeitos em sua passividade introjetam esses valores como normas naturalizadas e não se questionam sobre eles, apenas os reproduzem. O que acontece é que, segundo Foucault (2007), somandose a disciplinarização, estamos hoje em uma sociedade atravessada pela regulamentação e pelo biopoder, tal como discute Alvim (2013). Podemos dizer, de forma extremamente sintética, que se trata da estipulação de normas gerais que indicam o que é certo/normal e o que está fora dessa margem, o errado/ anormal. E a partir disso seguimos então o que está regulamentado como fatos naturais, dados, científicos, sobre os quais não nos questionamos.

A velocidade característica de nosso tempo, por sua vez, parece atuar a serviço da manutenção desse quadro de alienação. "Disciplinados, esquadrinhados pelo tempo e pela velocidade, temos nossos percursos comprimidos e perdemos a beleza do caminho, ansiosos pela chegada” (Alvim, 2013). Com base nas discussões de Pereira (2003) acerca do modo de vida atual, a autora afirma ainda, estarmos perdendo o momento do percurso e do itinerário, transformando-o numa espécie de não-lugar, uma vez que estamos sendo atravessados cada vez mais por formas aceleradas de comunicação e de locomoção.

Podemos dizer que se trata de uma vivência temporal que impossibilita sermos com presença, o que envolveria uma dimensão de disponibilidade, de abertura, de possibilidade de sentir e ser afetado, o que nos permitiria realizar nossas escolhas de forma autêntica. Sempre em atividade, perdemos a dimensão da experiência, da pausa necessária para que essa ocorra. A esse respeito, Bondía (2002) discorre:

(...) porque estamos sempre em atividade, porque estamos sempre mobilizados, não podemos parar. E, por não podermos parar, nada nos acontece. A ex- periência, a possibilidade de que algo nos aconteça ou nos toque, requer um gesto de interrupção, um gesto que é quase impossível nos tempos que correm: requer parar para pensar, parar para olhar, parar para escutar, pensar mais devagar, olhar mais devagar, e escutar mais devagar; parar para sentir, sentir mais devagar, demorar-se nos detalhes, suspender a opinião, suspender o juízo, suspender a vontade, suspender o automatismo da ação, cultivar a atenção e a delicadeza, abrir os olhos e os ouvidos, falar sobre o que nos acontece, aprender a lentidão, escutar aos outros, cultivar a arte do encontro, calar muito, ter paciência e dar-se tempo e espaço (p. 5)

É justamente por estarmos apressados que nos distanciamos do que é da ordem da experiência, isolados uns dos outros, individualizados e numa constante competição nos afastamos da possibilidade de nos encontrarmos com o outro, de "estar com". E nesse sentido, as queixas que vemos em nossos consultórios de pessoas que não conseguem estabelecer uma relação de intimidade, de diálogo genuíno parecem ser uma repercussão desse quadro.

Stela vivia correndo como todos nós, e em certo momento, por conta de uma doença que comprometeu temporariamente sua possibilidade de andar, se viu obrigada a parar. Essa parada parece ter lhe servido como esse gesto de interrupção que a obrigou a experienciar outra temporalidade. Foi obrigada a andar devagar, a dar-se um tempo, uma pausa. Foi neste episódio que ela finalmente pode não só se ver como também pode olhar para sua terapeuta, que deixou de ser mais um vulto na sua correria. Disse ter reencontrado "a beleza do caminho" e a possibilidade de desfrutar não só da sensação de vitória, sentida quando alcançamos um objetivo, mas também a vivência da experiência da travessia.

E é justamente no caminho que podem ocorrer os encontros, que o "estar com" se estabelece e que em presença temos a chance de nos surpreender. Porém, em uma sociedade individualista, que é ao mesmo tempo massificadora, as diferenças entre as pessoas tendem a ser anuladas e tolhidas, o que promove o fechamento de cada um em si nos distanciando do outro e das surpresas encontradas alhures, no "não-eu”. Assim, os indivíduos estão separados, porém homogêneos, ou seja, desconsiderados em sua singularidade e também em sua dimensão comum. O que está em jogo é um paradoxo: uma separação e ao mesmo tempo uma massificação que desarticula os coletivos. Os indivíduos são cada vez mais incapazes de uma real experiência e de se sentirem pertencentes a uma totalidade. "Tanto o eu quanto o outro se transformam em elementos de uma funcionalidade sistêmica, e os vínculos tendem a ser objetivamente utilitários” (Leopoldo e Silva 2012, p. 8).

Essa objetificação do outro e de nós mesmos está presente nos casos que recebemos em nossa clínica, aparecendo tanto na proflexão como na retroflexão e no egotismo. 
Parece-nos que essas interrupções funcionam na mesma dinâmica que tem operado a sociedade contemporânea: numa lógica de mercado, de objetificação e instrumentalização das relações. As trocas genuínas e as relações de reciprocidade são substituídas pela lógica do comércio, presente na sedução da proflexão, no controle ativo do egotismo e na autossuficiência da retroflexão. Somos sujeitos num mundo permeado por estes valores e é em meio a essa efervescência que nos constituímos. Em nossa busca por nos sentirmos aceitos, amados e incluídos nesse mundo acabamos por nos utilizar desses meios, que são os que conhecemos, para tentar atingir nossos fins. Temos nos engajado em nossas relações de formas parecidas com essa lógica que nos permeia, mas com isso temos perdido a dimensão mais genuína da relação: a de entrega e abertura. Para fugir do risco da imprevisibilidade que é inerente às relações humanas, lidamos seja com o outro seja com nós mesmos como objetos passíveis de serem controlados.

Assim, nos dias de hoje a ação espontânea, a diferença e a agressão - como entendidas pela Gestalt-terapia - não tem espaço. Passamos por um processo de massificação que nos iguala e, com isso, nos transforma em objetos passíveis de serem consumidos. "O diferente, errante, ambíguo, primitivo, sensual, representa ameaça ao instituído, sendo colocado na categoria do anormal" (Alvim et al., 2012, p. 186). Nesse contexto refratário às diferenças não há acolhimento, nem espaço para se manifestar fraquezas, impossibilidade, impotência.

Giacoia Jr (2012) afirma que se faz necessário adotarmos uma outra ideia de convivência, que se afirme justamente a partir da diferença, no espaço da alteridade radical.

Uma diferença que se assume, que não ignora, mas preserva a especificidade, a idiossincrasia - em definitivo, a singularidade, unicamente a partir da qual somos capazes de encetar um diálogo que não reconduza sempre as diferenças à figura triunfante do mesmo (p. 7).

Ao olharmos para a proposta do autor nos deparamos com a importância do diálogo que consiste no “(...) esteio primordial para a ideia de comunidade que deverá ser constituída ou construída a partir de um novo tipo de relação entre os homens. Buber a denominou "dialógica" ou relação Eu-Tu” (Zuben, 1984, p. 16).

Vemos, então, na rearticulação dos coletivos pela adoção de uma postura de diálogo e afirmação da alteridade, uma proposta de estabelecermos um espaço possível de esperança, em que sejam construídas relações onde haja espaço para o encontro, para a experiência de olhar e ser olhado, do reconhecimento, da empatia, do estar com, do re-estabelecimento do vínculo. Com isso, vemos uma possibilidade de uma rearticulação entre as partes e o todo.
Sob essa ótica, que, aliás, não se limita ao plano das relações íntimas e privadas, mas adquire pleno sentido se considerada no plano das relações internacionais, a alteridade, que deve sempre ser reconhecida, como base e ponto de partida - evitando, como precondição, uma assimilação desrespeitosa e arbitrária do outro, propiciando a convicção de que, no limite, somos todos espécie de um mesmo gênero, embora nossa comunicação seja somente possível sobre a base da inevitável diferença que nos define (Giacoia Jr, 2012, p. 9).

A lógica da alteridade re-estabelece a possibilidade do convívio tanto no nível das relações íntimas, quanto a nível mais amplo, o que o autor chama de relações internacionais. Os dois níveis se fazem necessários e funcionam de forma dialética. Consideramos, assim, que a clínica que se propõe e se estabelece dentro dessa lógica pode se configurar também enquanto um lugar que atua em prol da reversibilidade do quadro em que nos encontramos.

Acreditamos, tal como proposto por Cardella (2006) que: "Num mundo carente de relações humanizantes, o trabalho do terapeuta é fundamental. Criamos através da relação terapêutica, a possibilidade da pessoa resgatar a conexão primordial, re-ligando-a a si mesma e aos demais, constituindo ou restaurando a sua própria humanidade" (p. 110). A Gestalt-terapia busca recuperar o sentido da experiência concreta, do vivido e, para além disso, busca ampliar a awareness, ou seja, através da presentificação, restaurar nos sujeitos a dimensão do sensível e sua possibilidade criativa, de agressão. Ao fazer isso traz uma proposta de saúde baseada na espontaneidade e na possibilidade de sermos no mundo de forma mais crítica, menos alienada. Justamente por isso, sua terapia torna-se essa possibilidade de re-conexão, que também encontramos na experiência do coletivo.

Essa possibilidade de reconexão a qual estamos nos referindo diz de um re-estabelecimento da experiência, tal como é tomada por Bondía (2002) e a Gestalt-terapia. Com isso, consideramos necessário que nos arrisquemos diante do novo, pois a experiência, como já dissemos, comporta uma dimensão de risco e de travessia, de coragem para enfrentar a dimensão do perigo. Essa dimensão abarca tanto o júbilo quanto o sofrimento, que acaba por ser obliterado numa sociedade em que é proibido sofrer. A travessia, hoje, adquiriu um caráter de um não-lugar, não tem mais espaço diante da velocidade dos nossos tempos. "Corremos para um lugar intangível, que cada vez que nos aproximamos parece se deslocar" (Alvim, 2013). Direcionados sempre para o fim, perdemos o meio, e com isso o espaço da experiência, do acontecimento e da transformação. 


\section{Referências}

Agamben, G. (2009). O que é o contemporâneo? E outros ensaios. Chapecó: Argos.

Alvim, M. B. (2012). A clínica como poiética. Estudos e Pesquisas em Psicologia (UERJ), 12 (3), 1007-1023.

Alvim, M. B. (2013). Corporeidade e trabalho: o corpo-tempo que faz (e se faz) mundo. In: Andrea Pujol y Constanza Dall'Asta (Comp.). Trabajo, actividad y subjetividad. Debates Abiertos. 1. ed. Córdoba, Argentina: Universidad Nacional de Córdoba, Edición Digital bajo Licencia Creative Commons, 2013. E-book ISBN 978-987-29270-2-8.

Alvim, M. B.; Araújo, D. V.; Baptista, C. S.; Barroso, F. T. W.; Queiroz, K. M. F.; Da Silva, T. C. D. (2012). Corpo, fala e expressão: Diálogos entre a Gestalt-terapia e a filosofia de Merleau-Ponty. Revista IGT na Rede (Rio de Janeiro), 9 (17), 171-186.

Bondía, J. L. (2002). Notas sobre a experiência e o saber da experiência. Revista Brasileira de Educação, 19, 20-28.

Cardella, B. H. P. (2006). A construção do psicoterapeuta na atualidade. Revista da Abordagem Gestáltica, XII (2), 109-117.

Chauí, M. S. (2007). Público, privado, despotismo. In: Novaes, A. (Org). Ética. Coleção companhia de bolso. São Paulo: Ed. Schwarcz LTDA.

Clarkson, P. (1989). Gestalt counselling in action. London: Sage

Dufour, D. R. (2005). A arte de reduzir as cabeças. Sobre a nova servidão na sociedade ultraliberal. Rio de Janeiro: Companhia de Freud.

Foucault, M. (2007). Vigiar e Punir: história da violência nas prisões. Petrópolis: Vozes.

Giacoia Jr, O. (2012). Poder tolerar a diferença. Revista e, N. 158 São Paulo. Disponível em:http://www.sescsp.org.br/sesc/ revistas/revistas-link.cfm?Edicao-Id $=378 \&$ Artigo-ID $=57$ 78\&IDCategoria $=6646 \&$ reftype $=2$. Acesso em: 15.01.2012

Merleau-Ponty, M. (1990). O primado da percepção e suas conseqüências filosóficas. Campinas: Papirus (Original de 1946)

Merleau-Ponty, M. (1962). Um inédito de Maurice MerleauPonty. In: Revue de Métaphysique et de morale, in Libraire Armand Colin, N.4, p. 401-409.

Merleau-Ponty, M. (2000). O visível e o invisível. São Paulo: Editora Perspectiva (Original de 1964).

Miller, M. V. (1990). Rumo a uma psicologia do desconhecido. The Gestalt Journal, XIII (2), 12-20.

Perls, F.; Hefferline, R. \& Goodman, P. (1997). Gestalt-Terapia. São Paulo: Summus (Original de 1951).

Robine, J. M. (2003). Do campo à situação. Revista de Gestalt (Instituto Sedes Sapicns, São Paulo), 12.

Robine, J. M. (2006). O self desdobrado: perspectiva de campo em Gestalt-terapia. São Paulo: Summus.
Silva, F. L. (2012). Viver Junto. Revista e, N. 158 São Paulo. Disponível em: http://www.sescsp.org.br/sesc/revistas/revistaslink.cfm?Edicao-Id=378\&Artigo-ID=5778\&IDCategoria $=6$ 646\&reftype $=2$ Acesso em: 15.01.2012

Zuben, N. A. von (1984). Diálogo e Existência no Pensamento de Martin Buber. Publicado originalmente em Forghieri, Y. C. (Org.), Fenomenologia e Psicologia. Editora Cortez. São Paulo. Disponível em: http://www.fae.unicamp.br/vonzuben/ dialogo.html Acesso em: 12.12.2012.

Thatiana Caputo Domingues da Silva - Pós-Graduação em Psicologia Clínica na Abordagem Gestáltica pela Faculdade Paraíso IPGL - do Instituto de Pós-Graduação Grupo Lusófona e mestranda em Psicologia pela Universidade Federal do Rio de Janeiro. E-mail: thatiana.caputo@gmail.com

Camilla Santos Baptista - Especialista em saúde da família pela Escola Nacional de Saúde Pública - ENSP- da FIOCRUZ. E-mail: baptista.camilla@gmail.com

Mônica Botelho Alvim - Professora Adjunta do Instituto de Psicologia e do Programa de Pós-Graduação em Psicologia da Universidade Federal do Rio de Janeiro. Tem Graduação em Psicologia, Mestrado e Doutorado em Psicologia pela Universidade de Brasília (UnB). Endereço Institucional: Universidade Federal do Rio de Janeiro, Instituto de Psicologia. Av. Pasteur, 250, Campus da Praia Vermelha, Urca, 22290-240 - Rio de Janeiro. E-mail:mbalvim@gmail.com 